УДК 796.8

DOI https://doi.org/10.26661/2663-5925-2020-1-19

\title{
ДИНАМІКА ПОКАЗНИКІВ ЗАГАЛЬНОЇ ФІЗИЧНОЇ ПІДГОТОВЛЕНОСТІ ЮНАКІВ 15-16 РОКІВ У ПАНКРАТІОНІ УПРОДОВЖ РІЧНОГО ЦИКЛУ
}

\section{Согор О. Ю.}

аспірант кафедри фехтування, боксу та національних одноборств Львівський державний університет фізичної культури імені Івана Боберського вул. Костюшко, 11, Львів, Україна orcid.org/0000-0002-9511-9113 yukonbjj@gmail.com

\section{Ткач Ю. А.}

здобувач кафедри педагогіки і психології

Львівський державний університет фізичної культури імені Івана Боберського вул. Костюшко, 11, Львів, Україна orcid.org/0000-0003-2054-1579

tkach_yua@gmail.com

\section{Пітин М. П.}

доктор наук з фізичного виховання і спорту, професор, професор кафедри теорії спорту та фізичної культури

Львівський державний університет фізичної культури імені Івана Боберського вул. Костюшко, 11, Львів, Україна orcid.org/0000-0002-3537-4745 pityn7@gmail.com

\section{Окопний А. М.}

кандидат наук з фізичного виховання і спорту, доцент, доиент кафедри педагогіки і психології

Львівський держсавний університет фізичної культури імені Івана Боберського вул. Костюшко, 11, Львів, Україна orcid.org/0000-0001-5277-7952 okopnuy@rambler.ru

\section{Окопний В. I.}

директор

К3 «Солонківська дитяча юнацька спортивна школа» вул. Людкевича, 2, с. Солонка, Львівська область, Украӥна orcid.org/0000-0003-3970-342

$$
\text { Sol_sport@ukr.net }
$$


Ключові слова: спортсмени, показники, контроль, результати, єдиноборства.
Основні напрями розвитку теорії та методики управління навчальновиховним процесом та змагальною діяльністю охоплюють оптимальний підбір навчального змісту на різних етапах тривалої підготовки. За твердженнями фахівців етап спеціалізованої базової підготовки $є$ одним із найважливіших для підготовки та становлення спортсмена. На ньому розпочинається значне збільшення навантаження й формування індивідуального стилю змагальної діяльності. Метою дослідження $\epsilon$ визначення динаміки загальної фізичної підготовленості юнаків 15-16 років (етап спеціальної базової підготовки) в панкратіоні в річному циклі під впливом експериментальної та традиційної програм. Meтоди: теоретичний аналіз та узагальнення літературних джерел, аналіз документальних матеріалів, педагогічне тестування, педагогічний експеримент, методи математичної статистики. Протягом листопада 2018 - жовтня 2019 року було організовано та проведено формуючий педагогічний експеримент. Це передбачало запровадження авторської програми річної підготовки спортсменів на етапі спеціалізованої базової підготовки 3 панкратіону. Сформовано контрольну (21 спортсмен) та експериментальну (22 спортсмени) групи. Результати. Отримані результати спричинені великими обсягами тренувальних навантажень, спрямованих на розвиток фізичних якостей верхніх кінцівок традиційної програми та авторської підготовки, побудованих відповідно до структури та змісту змагальної діяльності та рекомендацій тренерів із панкратіону. На основі аналізу результатів загальної фізичної підготовленості спортсменів ми можемо спостерігатипозитивні зміни в експериментальній та контрольній групах. Однак спортсмени експериментальної групи мали дванадцять суттєвих змін на першому етапі і їх значення були вищими, ніж у їхніх колег із контрольної групи. В контрольній групі зафіксовано значні позитивні зміни за шістьма показниками загальної фізичної підготовленості. На другому етапі педагогічного експерименту кількість показників, які зазнали істотних змін, набула іншої конфігурації. Для експериментальної групи - дванадцять та для контрольної групи - вісім, але спостерігаються більш високі значення для більшості результатів контрольних вправ серед спортсменів експериментальної групи. 


\title{
DYNAMICS OF GENERAL PHYSICAL PREPAREDNESS INDICATORS OF YOUNG MEN 15-16 AGED IN PANKRATION DURING ANNUAL CYCLE
}

\author{
Sogor O. Yu. \\ Postgraduate Student at the Department of Fencing, Boxing and National Martial Arts \\ Lviv State University of Physical Culture named after Ivan Bobersky \\ Kostyushko str., 11, Lviv, Ukraine \\ orcid.org/0000-0002-9511-9113 \\ yukonbjj@gmail.com
}

Tkach Yu. A.

Postgraduate Student at the Department of Pedagogy and Psychology

Lviv State University of Physical Culture named after Ivan Bobersky

Kostyushko str., 11, Lviv, Ukraine

orcid.org/0000-0003-2054-1579

tkach_yua@gmail.com

Pityn M. P.

DSc (Physical Education and Sports), Professor,

Professor at the Department of Theory of Sports and Physical Culture

Lviv State University of Physical Culture named after Ivan Bobersky

Kosciuszko str., 11, Lviv, Ukraine

orcid.org/0000-0002-3537-4745

pityn7@gmail.com

\section{Okopny A. M.}

PhD (Physical Education and Sports), Associate Professor,

Senior Lecturer at the Department of Pedagogy and Psychology

Ivan Bobersky Lviv State University of Physical Culture

Kosciuszko str., 11, Lviv, Ukraine

orcid.org/0000-0001-5277-7952

okopnuy@rambler.ru

\section{Okopnyi V. I.}

Director

\author{
Municipal Institution "Solonkivska Children's Youth Sports School" \\ Lyudkevich str., 2, Solonka, Lviv region, Ukraine \\ orcid.org/ 0000-0003-3970-342, \\ Sol_sport@ukr.net
}

Key words: athletes, stage, control, results, combative sports.
The ain development directions of the theory and methodic of management educational and training process and competitive activity include optimal selection of the educational and training content at different stages of longterm training. According to experts, the stage of specialized basic training is one of the most important for the training and development of the athlete. A significant increase in workload and the formation of an individual style of competitive activity begins. The purpose of the study is to determine the dynamics of general physical preparedness of young men15-16 aged (stage of specialized basic training) in pankration in the annual cycle under the influence 
of experimental and traditional programs. Methods: theoretical analysis and generalization of literary sources, analysis of documentary materials, pedagogical testing, pedagogical experiment, methods of mathematical statistics. During November 2018 - October 2019, a formative pedagogical experiment was organized and conducted. It provided introduction of the author's program of annual training of athletes at the stage of specialized basic training in pankration. Control (21 athletes) and experimental (22 athletes) groups were formed. Results. The obtained results are caused by large amounts of training loads aimed at developing the physical qualities of the upper extremities of the traditional program and author's training, built in accordance with the structure and content of competitive activities and recommendations of pankration coaches. Based on the analys is results of the general physical preparedness level athletes, we can observe positive changes in experimental and control groups. However, athletes of the experimental group had 12 significant changes at the first stage and their values were higher than their colleagues in control group. At control group recorded significant positive changes in 6 indicators of general physical preparedness. At the second stage of the pedagogical experiment, the number of indicators that have undergone significant changes has acquired other configuration. For the experimental group - 12 and for control group -8 , but there are observed higher values for most results of control exercises among athletes in the experimental group.

Постановка проблеми й аналіз останніх досліджень. Основні напрями розвитку теорії та методики керування навчально-тренувальним процесом та змагальної діяльності охоплюють оптимальний добір змісту навчально-тренувального процесу на різних етапах $[1,8,13,15,16]$. Він повинен бути орієнтованим не лише на збільшення обсягу та інтенсивності тренувальних навантажень, але й на вдосконалення методології для забезпечення необхідних умов подальшого росту майстерності спортсменів.

За твердженнями фахівців, зазначений вік (етап спеціалізованої базової підготовки) є одним iз найважливіших для підготовки та становлення спортсмена, де розпочинається значне збільшення навантаження й формування індивідуального стилю змагальної діяльності. В цьому періоді вже повинне бути сформоване підгрунтя для якісного вдосконалення різних сторін підготовленості спортсмена. Тобто вони повинні набути достатнього рівня фізичної підготовленості $[2,3,4,5,10]$.

Проблематиці підготовки спортсменів у панкратіоні присвячена незначна кількість праць, проте більшість науковці наголошують на важливості правильної побудови тренувального процесу $[6,7,9,11,12]$. На їхнє переконання, якісна побудова навчально-тренувального процесу повинна передбачати вдосконалення спеціальних фізичних якостей, удосконалення засад техніки (професійний та прикладний аспекти), розвиток здібностей щодо оволодіння технікою ударів руками, ногами та боротьби, вдосконалення морально-вольових якостей тощо $[1,2,6,11,13]$. Загалом визначено, що досягнення високого рівня результативності спортсменів у панкратіоні неможливе без створення обгрунтованої бази з боку загальної фізичної підготовленості $[9,12,14]$.

Мета дослідження - 3'ясувати динаміку загальної фізичної підготовленості юнаків 15-16 років (етап спеціалізованої базової підготовки) в панкратіоні в річному циклі під впливом експериментальної та традиційної програм річної підготовки.

Використано такі методи: теоретичний аналіз та узагальнення літературних джерел (проведено пошук інформації та з'ясування обгрунтованості наукової проблематики дослідження); аналіз документальних матеріалів (вивчено структуру та зміст програми підготовки кваліфікованих спортсменів на етапі спеціалізованої базової підготовки в панкратіоні); педагогічне тестування (встановлено показники психофізіологічних характеристик спортсменів на етапі спеціалізованої базової підготовки в панкратіоні); педагогічний експеримент (перевірено ефективність авторського підходу до побудови структури та змісту програми підготовки спортсменів на етапі спеціалізованої базової підготовки з урахуванням сучасних вимог змагальної діяльності); методи математичної статистики (використано для опрацювання емпіричних даних на різних етапах дослідження).

Упродовж листопада 2018 - жовтня 2019 року організовано та проведено формувальний педагогічний експеримент, котрий передбачав упровадження авторської програми річної підготовки спортсменів на етапі спеціалізованої базової підготовки в панкратіоні. Сформовано контрольну (21 спортсмен) та експериментальну (22 спортсмени) 
групи 3 контингенту спортсменів на етапі спеціалізованої базової підготовки в панкратіоні.

У межах педагогічного експерименту запропоновано підбір вправ з урахуванням специфіки ведення змагальної діяльності спортсменами на етапі спеціалізованої базової підготовки; врахування прогнозованого рівня підготовленості, який міститься в наближенні до показників дорослих спортсменів; диференціація засобів підготовки 3 урахуванням варіативності манер ведення змагальної діяльності та побудови техніко-тактичних дій; зміна співвідношення обсягу виконання вправ iз загальної та спеціальної фізичної підготовки; підвищення загальної інтенсивності виконання вправ. Також запропоновано зменшити обсяги за розділами теоретична підготовки, технічна підготовка (вибірковий вплив), тактична підготовка (вибірковий вплив), складання контрольних нормативів, загальна та спеціальна фізична підготовка (вибірковий вплив), вільні та контрольні поєдинки; збільшити обсяги на спільне тренування iз спортсменами інших спортивних колективів, кількість зумовлених поєдинків, заняття іншими видами спорту; доповнити структуру розділом із використанням засобів сполученої дії техніко-тактичної підготовки та для фізичної підготовки засобами сполученої дії з техніко-тактичною підготовкою; використанням занять спорідненими видами спорту та конкретизовано співвідношення годин між участю у кваліфікаційних змаганнях i суддівською та інструкторською практикою.

Виклад основного матеріалу дослідження. Для отримання об'єктивної інформації ми застосували два блоки тестових вправ. Один спрямований на вивчення показників загальної та другий спеціальної фізичної підготовленості. У цій статті подано дані з першого блоку показників (табл. 1).

Для показників кистьової динамометрії (сильнішої руки) спостерігаються незначні прирости результатів упродовж дослідження. Лише окремі 3 них набувають достовірних значень $(\mathrm{p} \leq 0,05)$. Для представників експериментальної групи на першому етапі дослідження зміни становили всього $0,50 \%(p>0,05)$. Проте за час другого етапу педагогічного експерименту були більш вираженими та досягли достовірних значень (2,55 кгс, 6,91\%, $\mathrm{p} \leq 0,01)$.

Для представників контрольної групи спостерігаються схожі тенденції. Проте за перший макроцикл підготовки відбулось незначне ( $>0,05)$ погіршення результатів у межах середнього значення $1,04 \%$. Водночас за час другий етап педагогічного експерименту покращення результатів стало достовірним та становило вже $5,24 \%(\mathrm{p} \leq 0,01)$.

Зазначимо, що за показниками кистьової динамометрії на всіх контрольних зрізах (початок, середина та завершення педагогічного експерименту) достовірних відмінностей результатів не спостерігалось $(\mathrm{p}=0,32-0,90)$ та відсоткові значення становили 0,34-2,82\% переваги представників тієї чи іншої групи.

Певною мірою відмінну ситуацію ми можемо спостерігати для показників станової динамометрії. Спортсмени експериментальної групи на першому та на другому етапах педагогічного експерименту змогли продемонструвати підвищення результатів: спочатку на $1,26 \%(\mathrm{p} \leq 0,01)$ - перший

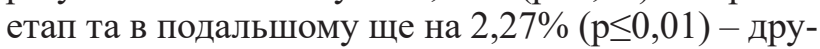
гий етап педагогічного експерименту.

На противагу цьому у представників контрольної групи достовірні зміни не були зафіксовані ні під час першого $(0,62 \%)$, ні під час другого етапу педагогічного експерименту $(0,41 \%)$. В обох випадках $\mathrm{p}>0,05$.

Проте зіставлення показників спортсменів на етапі спеціалізованої базової підготовки в панкратіоні за тестом «станова динамометрія» вказало на відсутність достовірних відмінностей на всіх етапах тестування. Це можна пояснити дещо вищими вихідними показниками для спортсменів контрольної групи, які переважали представників експериментальної групи на $1,42 \%(p=0,15)$ та поступово втратили цю несуттєву перевагу. Уже після завершення педагогічного експерименту незначну перевагу мали спортсмени експериментальної групи $(1,06 \%, \mathrm{p}=0,24)$.

Дещо інші за рівнем вірогідності результати отримані у процесі визначення показників вибухової сили спортсменів на етапі спеціалізованої базової підготовки в панкратіоні упродовж педагогічного експерименту.

Для представників експериментальної групи наявне достовірне $(2,46 \%, \mathrm{p} \leq 0,01)$ покращення показника вже за першу частину педагогічного експерименту. Ще більш вираженим стало покращення у другому макроциклі підготовки (3,58\%, $\mathrm{p} \leq 0,01)$. Водночас представники контрольної групи на першому етапі педагогічного експерименту також показали достовірні позитивні зрушення на 2,24\% від вихідного рівня $(\mathrm{p} \leq 0,01)$, проте у другому макроциклі підготовки темпи приростів дещо знизились та становили 1,10\% за показника $\mathrm{p}>0,05$.

Зазначене дозволило констатувати на перших двох тестуваннях (початок та середина педагогічного експерименту) відсутність достовірних відмінностей у рівні середньогрупових результатів представників експериментальної та контрольної груп (відповідно $0,47 \%$ та $0,68 \%(\mathrm{p}>0,05))$. Однак за підсумками річного циклу підготовки за допомогою використання авторської структури та змісту підготовки спортсменів на етапі спеціалізованої базової підготовки вдалось установили 
достовірні переваги у представників експериментальної групи $(3,16 \%, \mathrm{p}=0,01)$.

Представникам експериментальної групи внаслідок застосованого авторського підходу вдалось і на першому, й на другому етапах педагогічного експерименту достовірно покращити показники у вправі «кидок набивного м'яча» - відповідно $6,92 \%(p \leq 0,01)$ та $4,47 \%(p \leq 0,01)$. Спортсмени контрольної групи також мали значні позитивні зміни за результатами цього тесту, проте за відсотковими значеннями та рівнем вірогідності поступались своїм колегам. Прирости результатів становили $3,25 \%$ та $2,90 \%$ (в обох випадках $\mathrm{p} \leq 0,01)$. На міжгруповому рівні ми спостерігали поступове нарощення переваги представників експериментальної групи упродовж педагогічного експерименту від $1,01 \%$ до 4,10\%, зокрема на завершальному тестуванні воно сягнуло достовірного рівня $(\mathrm{p} \leq 0,01)$.
Розглядаючи результати тестування витривалості (тест «Біг 1000 м»), варто відзначити позитивний вплив обох методичних підходів до побудови програми річної підготовки на різних етапах педагогічного експерименту. Спортсмени експериментальної та контрольної груп достовірно $(\mathrm{p} \leq 0,01)$ покращували свої показники. Так, спортсмени на етапі спеціалізованої базової підготовки в панкратіоні експериментальної групи на першому етапі покращили результати на 4,48\% та другому - 5,97\%. Натомість представники контрольної групи на першому етапі покращили результат на $1,80 \%$, а на другому на 2,48\%. Ми отримали схожість середньогрупових результатів на першому (вихідному) та другому (середина) тестуваннях. Різниця становила всього $2,09 \%(\mathrm{p}>0,05)$ та $0,66 \%(\mathrm{p}>0,05)$. Проте на завершальному етапі завдяки пролонгованому впливу тренувальних навантажень

Показники загальної фізичної підготовленості спортсменів на етапі спеціалізованої базової підготовки в панкратіоні упродовж педагогічного експерименту

\begin{tabular}{|c|c|c|c|c|c|c|c|c|c|c|c|}
\hline \multirow{3}{*}{$\begin{array}{l}\text { № } \\
\text { 3/II }\end{array}$} & \multirow{3}{*}{\multicolumn{2}{|c|}{$\begin{array}{c}\text { Тест (контрольна } \\
\text { вправа) }\end{array}$}} & \multicolumn{6}{|c|}{ Етап проведення контролю } & \multirow{2}{*}{\multicolumn{3}{|c|}{$\mathbf{p}$}} \\
\hline & & & \multicolumn{2}{|c|}{ початок (1) } & \multicolumn{2}{|c|}{ середина (2) } & \multicolumn{2}{|c|}{ завершення (3) } & & & \\
\hline & & & $\mathbf{E \Gamma}$ & КГ & $\mathbf{E} \boldsymbol{\Gamma}$ & КГ & $\mathbf{E} \boldsymbol{\Gamma}$ & кГ & $\begin{array}{l}\text { EГ1- } \\
\text { КГ1 }\end{array}$ & $\begin{array}{l}\mathrm{E} \Gamma 2- \\
\text { КГ2 }\end{array}$ & $\begin{array}{l}\text { EГ3- } \\
\text { КГ3 }\end{array}$ \\
\hline \multirow{2}{*}{1} & \multirow{2}{*}{$\begin{array}{c}\text { Кистьова } \\
\text { динамометрія }\end{array}$} & $\mathrm{X}$ & 36,6 & 36,8 & 36,8 & 36,4 & 39,4 & 38,3 & \multirow{2}{*}{0,90} & \multirow{2}{*}{0,69} & \multirow{2}{*}{0,32} \\
\hline & & SD & 3,4 & 2,5 & 3,4 & 2,3 & 3,1 & 2,8 & & & \\
\hline \multirow{2}{*}{2} & \multirow{2}{*}{$\begin{array}{c}\text { Станова } \\
\text { динамометрія }\end{array}$} & $\mathrm{X}$ & 183,6 & 186,3 & 186,0 & 187,4 & 190,2 & 188,2 & \multirow{2}{*}{0,15} & \multirow{2}{*}{0,40} & \multirow[b]{2}{*}{0,24} \\
\hline & & SD & 5,3 & 4,2 & 4,6 & 4,5 & 3,7 & 4,9 & & & \\
\hline \multirow{2}{*}{3} & \multirow{2}{*}{$\begin{array}{c}\text { Стрибок } \\
\text { у довжину }\end{array}$} & $\mathrm{X}$ & 195,6 & 194,7 & 200,4 & 199,0 & 207,6 & 201,2 & \multirow{2}{*}{0,67} & \multirow{2}{*}{0,56} & \multirow{2}{*}{$\mathbf{0 , 0 1}$} \\
\hline & & SD & 5,7 & 5,5 & 7,1 & 5,4 & 7,6 & 4,7 & & & \\
\hline \multirow{2}{*}{4} & \multirow{2}{*}{$\begin{array}{c}\text { Кидок набив- } \\
\text { ного м’яча }\end{array}$} & $\mathrm{X}$ & 12,7 & 12,9 & 13,6 & 13,3 & 14,2 & 13,7 & \multirow{2}{*}{0,68} & \multirow{2}{*}{0,17} & \multirow{2}{*}{$\leq \mathbf{0 , 0 1}$} \\
\hline & & SD & 0,9 & 0,9 & 0,6 & 0,6 & 0,6 & 0,5 & & & \\
\hline \multirow[b]{2}{*}{5} & \multirow{2}{*}{ Біг 1000 м } & $\mathrm{X}$ & 243,3 & 238,3 & 232,4 & 233,9 & 218,5 & 228,1 & & & \\
\hline & & SD & 9,5 & 7,2 & 6,8 & 6,5 & 4,3 & 6,2 & 0,11 & 0,53 & $\leq \mathbf{0 , 0 1}$ \\
\hline 6 & $\mathrm{C}_{\mathrm{L}}$ & $\mathrm{X}$ & 4,0 & 4,0 & 4,0 & 4,0 & 3,9 & 3,9 & 054 & 071 & 076 \\
\hline 6 & БІГ $20 \mathrm{M}$ & SD & 0,1 & 0,1 & 0,1 & 0,1 & 0,1 & 0,1 & 0,54 & $0, / 1$ & $0, / 6$ \\
\hline 7 & $\begin{array}{c}\text { Згинання- } \\
\text { розгинання рук }\end{array}$ & $\mathrm{X}$ & 39,3 & 39,4 & 42,7 & 40,9 & 44,4 & 42,6 & 0,87 & $\leq 0,01$ & 0,01 \\
\hline & в упорі лежачи & SD & 2,9 & 2,4 & 1,2 & 2,0 & 1,7 & 1,7 & & & \\
\hline & Підйом тулуба & $\mathrm{X}$ & 20,3 & 20,9 & 22,0 & 21,4 & 23,1 & 22,7 & & & \\
\hline 8 & $\begin{array}{c}\text { в положення } \\
\text { сид за } 30 \text { с }\end{array}$ & SD & 1,4 & 1,4 & 1,3 & 1,2 & 1,3 & 1,2 & 0,26 & 0,19 & 0,36 \\
\hline 0 & Вис на зігну- & $\mathrm{X}$ & 22,9 & 27,7 & 28,5 & 30,4 & 34,0 & 32,8 & 0.0 & 024 & 020 \\
\hline y & тих руках & SD & 4,0 & 5,5 & 3,0 & 5,0 & 3,8 & 3,4 & & 0,24 & 0,38 \\
\hline 10 & Підтягування & $\mathrm{X}$ & 13,3 & 13,9 & 14,7 & 15,0 & 16,7 & 15,7 & 8 & 14 & 0.11 \\
\hline 10 & за $30 \mathrm{c}$ & SD & 1,2 & 1,2 & 1,1 & 1,0 & 1,7 & 1,4 & 0,18 & 0,44 & $0, \Pi 1$ \\
\hline 11 & Човниковий біг & $\mathrm{X}$ & 10,0 & 10,0 & 9,9 & 9,9 & 9,7 & 9,8 & 0.40 & 78 & 011 \\
\hline 11 & $4 \times 9$ м (c) & SD & 0,2 & 0,2 & 0,1 & 0,2 & 0,2 & 0,2 & 40 & 10 & 0,11 \\
\hline 12 & Нахил тулуба & $\mathrm{X}$ & 4,2 & 5,1 & 6,7 & 5,9 & 8,0 & 7,5 & 014 & 12 & 055 \\
\hline 12 & сидячи & SD & 1,5 & 1,8 & 1,5 & 1,2 & 1,9 & 2,0 & 0,14 & 12 & (5, \\
\hline 13 & Викрут лінійки & $\mathrm{X}$ & 49,0 & 45,3 & 45,9 & 44,3 & 40,5 & 40,4 & $<001$ & 010 & 0.91 \\
\hline 13 & за спину & SD & 2,8 & 2,3 & 1,7 & 2,9 & 3,0 & 2,4 & $=0,01$ & 0,10 & 0,91 \\
\hline
\end{tabular}


отримана перевага представників експериментальної групи на 4,21\% (p $\leq 0,01)$.

У тесті «Біг 20 м» відсутні достовірні зміни для спортсменів не етапі спеціалізованої базової підготовки в панкратіоні обох груп. За відносними значеннями зміни в експериментальній групі становили 1,15-2,14\% (p>0,05), а в контрольній - 1,06-1,20\% (p>0,05). На всіх етапах відсутні достовірні відмінності, різниця результатів становила $0,37-0,67 \%(\mathrm{p}>0,05)$ на користь однієї чи іншої групи спортсменів.

За одним із проявів («Згинання-розгинання рук в упорі лежачи») спостерігаємо виражені зміни показників за час педагогічного експерименту. Спортсмени експериментальної групи за перший етап покращили свої результати на 8,80\% (p $\leq 0,01)$ та за другий - ще на $3,83 \%(p \leq 0,01)$. Схожі тенденції спостерігаються у представників контрольної групи. Проте набуті значення становили 3,76\% $(p \leq 0,01)$ в першому макроциклі та 4,19\% $(p \leq 0,01)-$ у другому макроциклі підготовки. У середині педагогічного експерименту спортсмени експериментальної групи переважали своїх колег на 4,46\% $(\mathrm{p} \leq 0,01)$ та після завершення $-4,09 \%(\mathrm{p}=0,01)$.

Спортсмени експериментальної групи достовірно покращували свої результати з тестом «Підйом тулуба в положення сид за 30 с» як на першому $(8,74 \%, p \leq 0,01)$, так i на другому $(4,74 \%$, $\mathrm{p} \leq 0,01)$ етапах педагогічного експерименту. Так само представники контрольної групи на першому етапі покращили результати в цій вправі на 2,58\% (p>0,05) та другому $-5,78 \%(p \leq 0,01)$. Порівнявши результати тесту між представниками експериментальної та контрольної груп, було встановлено, що на всіх етапах тестування відсутні достовірні відмінності, різниця результатів становила $1,87-3,02 \%(\mathrm{p}=0,19-0,36)$.

На відміну від попередніх тестів, у «Висі на зігнутих руках» на початку педагогічного експерименту спостерігалась перевага представників контрольної над експериментальною групою. Вона становила $17,34 \%(\mathrm{p} \leq 0,01)$. Завдяки впливам тренувальних навантажень, здебільшого авторської програми, вдалось дещо зрівняти результати. На другому тестуванні різниця вже становила 6,19\% $(\mathrm{p}=0,24)$ та третьому $-3,77 \%(\mathrm{p}>0,05)$, проте вже на користь представників експериментальної групи. Упродовж першого макроциклу спортсменам удалось підвищити результати на 24,40\% $(\mathrm{p} \leq 0,01)$ та другого - ще на 19,46\% (p $\leq 0,01)$. Такі значення, здебільшого пов'язані із суттєво нижчим вихідним рівнем. Водночас представники контрольної групи на першому етапі педагогічного експерименту покращили результати на $11,64 \%(\mathrm{p}=0,02)$ та другому - ще на 7,99\% $(\mathrm{p}=0,02)$.

За отриманими результатами спостерігаємо загалом позитивні зміни для представників як експериментальної, так i контрольної груп у тесті «Підтягування на перекладині за 30 с». Це $\epsilon$ достатньо очікуваним, оскільки спортсмени перебувають досвіду на етапі спеціалізованої базової підготовки та річний цикл однозначно має відображатись на рівні підготовленості завдяки природного приросту функціональних можливостей та якісним тренувальним та змагальним впливам.

Таким чином, зафіксовано, що спортсмени експериментальної групи на першому етапі педагогічного експерименту змогли покращити свої результати в цій вправі на $10,58 \%(\mathrm{p} \leq 0,01)$ та на другому етапі - на $13,27(\mathrm{p} \leq 0,01)$. Водночас їхні колеги 3 контрольної групи набули на першому етапі результатів на 8,58\% $(\mathrm{p}=0,02)$ вищі за початкові, та на другому - на 4,43\%, проте без доведеної достовірності ( $\mathrm{p}=0,17)$.

Проте якщо на початковому етапі та в середині перевага була на стороні спортсменів контрольної групи 4,22\% та 2,13\% відповідно, то після завершення вищими виявились результати спортсменів на етапі спеціалізованої базової підготовки в панкратіоні експериментальної групи - 6,16\%.

Консервативність щодо розвитку швидкісних якостей спортсменів ми можемо підтвердити й за даними результатів тесту «Човниковий біг 4х9м». На всіх етапах тестування не було достовірних змін ( $>>0,05)$ для спортсменів обох груп.

Останній блок тестів був спрямований на визначення гнучкості хребетного стовпа й кульшових суглобів та рухливості у плечових суглобах. За результатами тесту «Нахил тулуба сидячи» можна констатувати низькі значення вихідних результатів для представників як експериментальної, так і контрольної груп. За час першого етапу педагогічного експерименту спортсмени експериментальної групи покращили результат на 59,14\% $(\mathrm{p} \leq 0,01)$, а контрольної - 3 вираженими відсотковими значеннями $(18,02 \%)$ - ці значення не набули критичних значень достовірності $(\mathrm{p}=0,21)$. Проте на другому етапі педагогічного експерименту представники обох груп змогли достовірно підвищити свої результати. Спортсмени експериментальної групи на 18,24\% ( $\leq \leq 0,05)$, а контрольної - на $27,42 \%(\mathrm{p} \leq 0,05)$. Саме завдяки таким змінам упродовж усіх етапів тестування не спостерігається відмінностей між групами спортсменів на етапі спеціалізованої базової підготовки в панкратіоні. Відмінності перебувають у діапазоні 5,72-17,80\% на користь тієї чи іншої групи $(\mathrm{p}=0,12-0,55)$.

Проаналізувавши показники рухливості у плечових суглобах, було виявлено, що за перший макроцикл (етап педагогічного експерименту) представники експериментальної групи досить суттєво покращили свої результати - на 6,40\% $(\mathrm{p} \leq 0,01)$. Також достовірні позитивні зміни зафік- 
совані і для другого етапу педагогічного експерименту, вони становили $11,60 \%(\mathrm{p} \leq 0,01)$. Для спортсменів на етапі спеціалізованої базової підготовки контрольної групи значення покращення теж були високими, проте на першому етапі педагогічного експерименту відсоток змін становив 2,04 ( $>00,05)$, а вже у другому вони досягли достовірного рівня $(\mathrm{p} \leq 0,01)$ та становили $8,81 \%$ від попереднього тестування.

Зазначимо, що на початку педагогічного експерименту представники контрольної групи мали достовірно вищі показники рухливості у плечових суглобах, що на $8,09 \%(\mathrm{p} \leq 0,01)$ перевищувало результати спортсменів експериментальної групи. За час реалізації програми річної підготовки спортсменам на етапі спеціалізованої базової підготовки вдалось поступово наблизитись до результатів представників контрольної групи та знівелювати наявну на початку дослідження. У середині дослідження відмінності становили вже 3,45\% (p=0,10), а після завершення педагогічного експерименту - 0,29\% $(\mathrm{p}=0,91)$.

Отримані результати свідчать про наявну динаміку підготовленості за всіма досліджуваними показниками загальної фізичної підготовленості спортсменів на етапі спеціалізованої базової підготовки. Проте рівень змін та їх вірогідність мають певні відмінності для представників як контрольної, так й експериментальної груп. Це спостерігається під час внуртрішньогрупового та міжгрупового зіставлення результатів тестування.

На наш погляд, це не суттєво позначилось на загальному рівні загальної фізичної підготовленості спортсменів та може бути пов'язане 3 певними особливостями тренувальних навантажень, котрі використані у програмі підготовки для спортсменів контрольної групи. Отримані результати можуть бути викликані великими обсягами тренувальних навантажень, спрямованих на розвиток фізичних якостей верхніх кінцівок, притаманних як для традиційної програми, так й авторської підготовки, яка побудована відповідно до структури та змісту змагальної діяльності та рекомендації тренерів із панкратіону [9, 11, 12, 14].

Висновки. За підсумками аналізування рівня загальної фізичної підготовленості спортсменів на етапі спеціалізованої базової підготовки можемо спостерігати позитивні зміни у представників як експериментальної, так і контрольної груп. Проте у спортсменів експериментальної групи загальна кількість достовірних змін на першому етапі становила 12 та їхні значення були вищими за значення колег iз контрольної групи. В контрольній же групі зафіксовані достовірні позитивні зміни за 6-ма показниками загальної фізичної підготовленості.

На другому етапі педагогічного експерименту кількість показників, які зазнали достовірних змін, набула іншої конфігурації. Для експериментальної групи - 12 та контрольної групи - 8, проте знову ж таки спостерігаються дещо вищі значення за більшістю результатів контрольних вправ серед спортсменів на етапі спеціалізованої базової підготовки експериментальної групи.

Перспективи подальших досліджень передбачають з'ясування ефективності авторської програми за іншими групами показників спортсменів на етапі спеціалізованої базової підготовки в панкратіоні.

\section{ЛІТЕРАТУРА}

1. Безкоровайний С.Б. Сучасні підходи вдосконалення фізичної підготовки студентів-єдиноборців. Молодий вчений, Луцьк. 2019. Вип. 4.1(68.1). С. 175-178.

2. Бекас О.О. Паламарчук Ю.Г. Процес удосконалення фізичної підготовленості борців-дзюдоїстів протягом річного макроциклу на етапі спеціалізованої базової підготовки. Фізичне виховання, спорт і культура здоров'я у сучасному суспільстві. Луцьк, 2009. № 2. С. 88-91.

3. Білецький С.В., Пономарьов В.О. Теоретико-методологічні напрямки перекваліфікації спортсменів борцівських стилів на рукопашний бій. Сдиноборства. Харків, 2017. Вип. 2(4). С. 7-10.

4. Гаранин Е.А., Кузнецов С.А. Экспериментальная методика подготовки бойцов армейского рукопашного боя на основе учета индивидуального стиля ведения спортивного поединка. Физическая культура, спорт - наука и практика. Кубань, 2015. № 4. С. 5-12.

5. Гуцул Н.З. Особливості спеціальної фізичної підготовки єдиноборців на етапі спеціалізованої базової підготовки. Фізична культура, спорт та здоров'я начії. Вінниця, 2018. Вип. 24. С. 204-209.

6. Долженко М.Ю. Психологическая подготовка спортсменов-студентов к соревновательной деятельности в панкратионе. Ukrainian Journal of Ecology. Мелітополь, 2015, Вип. 1а(14). С. 42-45.

7. Дягель П.И., Банку Т.А. Комплексная оценка подготовленности юношей 16-17 лет, занимающихся смешанным боевым единоборством (ММА). Развитие образования, педагогики и психологии в современном мире: сб. науч. тр. Воронеж, 2015. С. 77-79.

8. Ільницький I.О., Окопний А.М., Палатний А.І. Удосконалення фізичної підготовленості учнів ліцеїв 3 посиленою військово-фізичною підготовкою за допомогою програм секційних занять з боксу. Фізична активність, здоров'я і спорт. Львів, 2017. № 3(29). С. 14-23. 
9. Коньков Д.А. Методические особенности построения тренировочного процесса в панкратионе. Известия Российского государственного педагогического университета им. А.И. Гериена. Санкт-Петербург, 2008. № 58. С. 399-405.

10. Лю Юн Цянь. Вариативность физической подготовки дзюдоистов на этапе углубленной специализации. Физическая культура, спорт - наука и практика. Кубань, 2015. № 4. С. 13-19.

11. Наконечний І.Ю. Взаємозв'язок спеціальної фізичної підготовки та психологічного супроводу в багаторічній підготовці висококваліфікованих спортсменів 3 панкратіону. Молодий вчений. Луцьк, 2017. Вип. 3.1(43.1). С. 221-226.

12. Наконечний І.Ю. Взаємозв'язок спеціальної фізичної та техніко-тактичної підготовки висококваліфікованих спортсменів з панкратіону. Вісник Прикарпатського університету. Серія: Фізична культура. Івано-Франківськ, 2020. № 3. С. 62-67.

13. Платонов В.Н. Система подготовки спортсменов в олимпийском спорте. Общая теория и её практические приложения: учеб. тренера высш. квалиф. Киев: Олимпийская литература, 2004. 808 с.

14. Скрипка I.M., Чередніченко С.В. Результати впровадження програми з загальної та спеціальної фізичної підготовки з елементами панкратіону у процес фізичного виховання учнів молодших класів. Сдиноборства. Харків, 2018. № 4(10). С. 52-61.

15. Филимонов В.И., Нигмедзянов Р.А. Бокс, кикбоксинг, рукопашный бой подготовка в контактных видах единоборств. Москва : ИНСАН, 1999. 416 с.

16. Чернозуб А.А., Адамович Р.Г., Штефюк І.К. Наукове обгрунтування структури та змісту тренувального навантаження спортсменів, які спеціалізуються у рукопашному бої. Украӥнський журнал медицини, біологіï та спорту. Миколаїв, 2019. Вип. 4. № 5(21). С. 395-402.

\section{REFERENCES}

1. Bezkorovayniy S.B. (2019) Suchasni pidkhodi vdoskonalennya fizichnoi pidgotovki studentiv-yedinobortsiv [Modern approaches to improving the physical training of martial arts students]. Molodiy vcheniy, no. 4.1 (68.1), pp. 175-178.

2. Bekas O. Palamarchuk Yu. (2009) Protses udoskonalennya fizichnoi pidgotovlenosti bortsiv-dzyudoistiv protyagom richnogo makrotsiklu na etapi spetsializovanoi bazovoi pidgotovki [The process of improving the physical fitness of judo fighters during the annual macrocycle at the stage of specialized basic training]. Fizichne vikhovannya, sport i kultura zdorov'ya u suchasnomu suspilstvi, no. 2, pp. 88-91.

3. Biletskiy S.V., Ponomarov V.O. (2017) Teoretiko-metodologichni napryamki perekvalifikatsiyi sportsmeniv bortsivskikh stiliv na rukopashniy biy [Theoretical and methodological directions of retraining of wrestling athletes for hand-to-hand combat]. Yedinoborstva, vol. 2 (4), pp. 7-10

4. Garanin E.A., Kuznetsov S.A. (2015) Eksperimentalnaya metodika podgotovki boytsov armeyskogo rukopashnogo boya na osnove ucheta individualnogo stilya vedeniya sportivnogo poedinka [Experimental technique of training fighters of army hand-to-hand combat on the basis of the account of individual style of conducting a sports duel]. Fizicheskaya kultura, sport - nauka i praktika, no. 4, pp. 5-12.

5. Gutsul N.Z. (2018) Osoblivosti spetsialnoi fizichnoi pidgotovki yedinobortsiv na etapi spetsializovanoi bazovoi pidgotovki [Features of special physical training of wrestlers at the stage of specialized basic training]. Fizichna kultura, sport ta zdorov'ya natsiyi. Vinnitsya, vol. 24, pp. 204-209.

6. Dolzhenko M. Yu. (2015) Psikhologicheskaya podgotovka sportsmenov-studentov k sorevnovatelnoy deyatelnosti v pankratione [Psychological preparation of student-athletes for competitive activity in pankration]. Ukrainian Journal of Ecology, vol. 1a (14), pp. 42-45.

7. Dyagel P.I., Banku T.A. (2015) Kompleksnaya otsenka podgotovlennosti yunoshey 16-17 let, zanimayushchikhsya smeshannym boevym edinoborstvom (MMA) [Comprehensive assessment of the readiness of young men aged 16-17 engaged in mixed martial arts]. Razvitie obrazovaniya, pedagogiki i psikhologii $v$ sovremennom mire: sb. nauch. tr. Voronezh, pp. 77-79.

8. Ilnitskiy I., Okopniy A., Palatniy A. (2017) Udoskonalennya fizichnoi pidgotovlenosti uchniv litseyiv z posilenoyu viyskovo-fizichnoyu pidgotovkoyu za dopomogoyu program sektsiynikh zanyat z boksu [Improving the physical fitness of lyceum students with enhanced military and physical training through programs of sectional boxing classes]. Fizichna aktivnist, zdorov'ya i sport, no. 3 (29), pp. 14-23.

9. Konkov D. A. (2008) Metodicheskie osobennosti postroeniya trenirovochnogo protsessa v pankratione [Methodical features of construction of training process in pankration]. Izvestiya Rossiyskogo gosudarstvennogo pedagogicheskogo universiteta im. A.I. Gertsena, no. 58, pp. 399-405.

10. Lyu Yun Tsyan (2015) Variativnost fizicheskoy podgotovki dzyudoistov na etape uglublennoy spetsializatsii [Variability of physical training of judokas at the stage of in-depth specialization]. Fizicheskaya kultura, sport-nauka i praktika, no. 4, pp. 13-19. 
11. Nakonechniy I.Yu. (2017) Vzayemozv'yazok spetsialnoi fizichnoi pidgotovki ta psikhologichnogo suprovodu $\mathrm{v}$ bagatorichniy pidgotovtsi visokokvalifikovanikh sportsmeniv z pankrationu [Relationship between special physical training and psychological support in long-term training of highly qualified pankration athletes]. Molodiy vcheniy, vol. 3.1 (43.1), pp. 221-226.

12. Nakonechniy I. (2020) Vzayemozv'yazok spetsialnoi fizichnoi ta tekhniko-taktichnoi pidgotovki visokokvalifikovanikh sportsmeniv z pankrationu [Relationship between special physical and technical-tactical training of highly qualified pankration athletes]. Visnik Prikarpatskogo universitetu. Seriya: Fizichna kultura, no. 3, pp. 62-67.

13. Platonov V.N. (2004) Sistema podgotovki sportsmenov v olimpiyskom sporte [The system of training athletes in Olympic sports. General theory and its practical applications]. Obshchaya teoriya i eyo prakticheskie prilozheniya: ucheb. trenera vyssh. kvalif. Kiev: Olimpiyskaya literatura. (in Russian)

14. Skripka I. M., Cherednichenko S. V. (2018) Rezultati vprovadzhennya programi z zagalno ta spetsialnoi fizichnoi pidgotovki z elementami pankrationu v protses fizichnogo vikhovannya uchniv molodshikh klasiv [The results of the implementation of the program of general and special physical training with elements of pankration in the process of physical education of primary school students]. Yedinoborstva, no. 4(10), pp. 52-61

15. Filimonov V. I., Nigmedzyanov R. A. (1999) Boks, kikboksing, rukopashnyi boy podgotovka v kontaktnykh vidakh edinoborstv [Boxing, kickboxing, hand-to-hand combat training in contact martial arts]. Moskva: INSAN. (in Russian)

16. Chernozub A. A., Adamovich R. G., Shtefyuk I. K. (2019) Naukove obgruntuvannya strukturi ta zmistu trenuvalnogo navantazhennya sportsmeniv, yaki spetsializuyutsya u rukopashnomu boi [Scientific substantiation of the structure and content of the training load of athletes who specialize in hand-to-hand combat]. Ukrainskiy zhurnal meditsini, biologiyi ta sportu, vol. 4, no. 5 (21), pp. 395-402. 